\title{
Fluid overload independent of acute kidney injury predicts poor outcomes in neonates following congenital heart surgery
}

\author{
Kenneth E. Mah ${ }^{1,2} \cdot$ Shiying Hao ${ }^{2,3} \cdot$ Scott M. Sutherland ${ }^{2,4} \cdot$ David M. Kwiatkowski ${ }^{1,2}$. \\ David M. Axelrod ${ }^{1,2}$ - Christopher S. Almond ${ }^{1,2} \cdot$ Catherine D. Krawczeski $^{1,2}$. \\ Andrew Y. Shin ${ }^{1,2,5,6}$
}

Received: 31 May 2017 /Revised: 9 September 2017 / Accepted: 28 September 2017 /Published online: 11 November 2017

(C) IPNA 2017

\begin{abstract}
Background Fluid overload (FO) is common after neonatal congenital heart surgery and may contribute to mortality and morbidity. It is unclear if the effects of FO are independent of acute kidney injury (AKI).

Methods This was a retrospective cohort study which examined neonates (age $<30$ days) who underwent cardiopulmonary bypass in a university-affiliated children's hospital between 20 October 2010 and 31 December 2012. Demographic information, risk adjustment for congenital heart surgery score, surgery type, cardiopulmonary bypass time, cross-clamp time, and vasoactive inotrope score were recorded. FO [(fluid in-out)/pre-operative weight] and AKI defined by Kidney Disease Improving Global Outcomes serum creatinine criteria were calculated. Outcomes were all-
\end{abstract}

Andrew Y. Shin

drewshin@stanford.edu

1 Division of Pediatric Cardiology, Department of Pediatrics, Stanford Cardiovascular Research Institute, Stanford University School of Medicine, Stanford, CA, USA

2 Lucile Packard Children's Hospital Stanford, 725 Welch Road, Palo Alto, CA 94304, USA

3 Division of Pediatric Cardiac Surgery, Department of Cardiothoracic Surgery, Stanford University School of Medicine, Stanford, CA, USA

4 Division of Nephrology, Department of Pediatrics, Stanford University School of Medicine, Stanford, CA, USA

5 Center for Quality and Clinical Effectiveness, Stanford Children's Health, Stanford University Medical Center, Palo Alto, CA, USA

6 Lucile Packard Children's Hospital Stanford, Stanford University Medical Center, 750 Welch Road, Ste 305, Palo Alto, CA 94304, USA cause, in-hospital mortality and median postoperative hospital and intensive care unit lengths of stay.

Results Overall, 167 neonates underwent cardiac surgery using cardiopulmonary bypass in the study period, of whom 117 met the inclusion criteria. Of the 117 neonates included in the study, 76 (65\%) patients developed significant FO $(>10 \%)$, and $25(21 \%)$ developed AKI $\geq$ Stage 2 . When analyzed as FO cohorts $(<10 \%, 10-20 \%,>20 \%$ FO), patients with greater FO were more likely to have AKI (9.8 vs. 18.2 vs. $52.4 \%$, respectively, with $\mathrm{AKI} \geq$ stage $2 ; p=0.013$ ) and a higher vasoactive-inotrope score, and be premature. In the multivariable regression analyses of patients without AKI, FO was independently associated with hospital and intensive care unit lengths of stay [0.322 extra days $(p=0.029)$ and 0.468 extra days $(p<0.001)$, respectively, per $1 \%$ FO increase). In all patients, FO was also associated with mortality [odds ratio 1.058 (5.8\% greater odds of mortality per $1 \% \mathrm{FO}$ increase); 95\% confidence interval 1.008,1.125; $p=0.032$ ]. Conclusions Fluid overload is an important independent contributor to outcomes in neonates following congenital heart surgery. Careful fluid management after cardiac surgery in neonates with and without AKI is warranted.

Keywords Congenital heart defects .

Cardiopulmonary bypass $\cdot$ Postoperative care $\cdot$ Fluid balance . Acute kidney injury $\cdot$ Critical care outcomes

\section{Introduction}

Fluid overload (FO) occurs commonly after congenital heart surgery with up to $30-68 \%$ of patients experiencing at least $10 \%$ FO [1]. In studies of non-cardiac surgical patients, FO has been associated with significant morbidity, including prolonged duration of mechanical ventilation, increased 
hospital and intensive care lengths of stay (LOS), multisystem organ failure, and increased mortality in certain populations [2-4]. There is emerging evidence that FO may similarly affect morbidity and mortality after cardiac surgery. FO has been implicated in increased ventilator days, greater vasoactiveinotrope score (VIS), longer total hospital and intensive care LOS, increased incidence of low cardiac output syndrome, and mortality [5-7].

Neonates undergoing congenital heart surgery are at increased risk of FO due to the need for cardiopulmonary bypass (CPB), aortic cross-clamp, and often the prolonged duration of both [8]. CPB triggers a systemic inflammatory response characterized by fluid shifts and increased blood vessel permeability $[9,10]$. In neonates, this cascade, in addition to the higher volume load per body surface area with CPB circuit priming compared to older patients, predisposes patients to developing capillary leak syndrome [11]. Aortic cross-clamp is defined by an obligate period of cardiac ischemia during which tissue may be damaged, resulting in higher risk for the development of low cardiac output syndrome. In a state of inadequate perfusion, end organs are damaged and become dysfunctional, especially the neonatal kidneys, which inherently are at increased risk due to renal tubular immaturity. Consequently, neonates are often vulnerable to FO which in turn amplifies the significance of acute kidney injury (AKI) following cardiac surgery [12-14].

It is unclear whether FO independent of AKI is important in this patient population. Previous studies have suggested FO in the postoperative period to be associated with poor outcomes $[1,5-7,15,16]$. However, these studies do not separate the influence of AKI from the effects of FO. Furthermore, studies specific to cardiac surgery or studies evaluating time to negative fluid balance have not shown a difference, and few studies have looked at neonates as a specific patient population [17].

The purpose of our study was to understand the relationship between FO and outcomes in neonates recovering from congenital heart surgery with CPB and aortic cross-clamp. We hypothesized that FO, independent of AKI, is associated with poor outcomes.

\section{Materials and methods}

\section{Study design and patients}

This is a retrospective cohort study performed at Lucile Packard Children's Hospital Stanford. All neonates (age $<30$ days) who underwent congenital heart surgery between 20 October 2010 and 31 December 2012 were eligible for inclusion. Patients were excluded if they did not require $\mathrm{CPB}$, did not require aortic cross-clamp, required preoperative extracorporeal membrane oxygenation, had undergone previous cardiac surgery at an outside institution, or had insufficient data recorded in the medical record. The study protocol was approved by the Institutional Review Board of Stanford University School of Medicine. No informed consent was required.

\section{Demographic and clinical data}

Demographic variables included age, gender, race, ethnicity, weight, chromosomal abnormalities (22q11.2 deletion, Trisomy 21, 45X, and deletion/duplication variants detected on comparative genomic hybridization), and prematurity (born at gestational age $\leq 37$ weeks). Anatomic and surgical characteristics were cataloged as single ventricle palliation or biventricular repair. We used Risk Adjustment for Congenital Heart Surgery 1 (RACHS-1) method to classify the patients by surgical complexity [18]. VIS at $48 \mathrm{~h}$ postoperatively was used to denote severity of illness $[19,20]$.

\section{Clinical management}

All patients recovered postoperatively in our pediatric cardiovascular intensive care unit (CVICU). At Lucile Packard Children's Hospital Stanford, patients requiring CPB empirically receive methylprednisolone at the initiation of CPB. A combination of volume-reduced and routine blood products is used both on and off CPB. While conventional ultrafiltration is performed, other intra-operative support strategies, including deep hypothermic circulatory arrest and modified ultrafiltration, are not utilized. Indwelling bladder catheters are routinely placed intra-operatively but peritoneal drains are not. Postoperatively, patients are fluid restricted to two-thirds of the maintenance fluid intake, including intravenous fluids and medications, according to the standard Holliday and Segar method [21]. Intravenous fluid is routinely a dextrosecontaining crystalloid fluid, such as D5-10\% 1/4-1/2 normal saline. For volume resuscitation, normal saline and $5 \%$ albumin boluses are typically used in aliquots of $5 \mathrm{~mL}$ per kilogram body weight. Blood products, such as packed red blood cells, platelets, and cryoprecipitate, are not typically volumereduced. The blood transfused at our center is stored in AS-3 preservative. Postoperative steroid administration is not standard.

\section{Definitions}

Acute kidney injury was calculated according to the Kidney Disease: Improving Global Outcomes (KDIGO) serum creatinine criteria [22]. KDIGO criteria were used to define AKI because they offer a balance between sensitivity and specificity that the pRIFLE (pediatric Risk, Injury, Failure, Loss, End Stage Renal Disease) and AKIN (Acute Kidney Injury Network) criteria correspondingly represent [23]. While 
utilizing any of the three definitions would be valid, KDIGO criteria were chosen to most fully capture the AKI outcome signal. Furthermore, this choice is consistent with the movement in the AKI literature toward the use of KDIGO criteria in all groups, including neonatal and pediatric populations [24-27]. KDIGO stages AKI as follows: Stage 1: creatinine increases to 1.5- to1.9-fold $\times$ baseline or an absolute increase of $\geq 0.3 \mathrm{mg} / \mathrm{dL}$ within $48 \mathrm{~h}$; Stage 2 : creatinine increases to 2.0- to 2.9-fold $\times$ baseline; Stage 3 : creatinine increases to threefold $\times$ baseline or an absolute increase to $\geq 4.0 \mathrm{mg} / \mathrm{dL}$ or receipt of renal replacement therapy. Creatinine data through to postoperative day 7 were used to categorize patients based on their peak AKI stage.

FO was calculated as a percentage of pre-operative weight by: [(total fluid in - total fluid out) / pre-operative weight $] \times$ 100. Total fluids were used rather than weight because postoperative daily weights are not routinely obtained due to safety and inaccuracy concerns [28]. FO was calculated as a running total for postoperative days $0-5$. Patients were categorized based on their maximum FO experienced. To be consistent with prior FO studies, we used commonly accepted cutoffs for assessing FO in clinical practice $(<10 \%, 10-20 \%$, and $>20 \%$ FO) to create cohorts.

Our model controlled for type of surgical repair, RACHS-1 score, CPB time, cross-clamp time, VIS, age, gender, race, ethnicity, weight, chromosomal abnormalities, prematurity, and AKI.

\section{Outcome}

Our primary endpoint was all-cause, in-hospital mortality. Our secondary endpoint was postoperative LOS. LOS was stratified into days spent in the CVICU and total days spent in the hospital, excluding pre-operative LOS.

\section{Statistical analysis}

Descriptive statistics with variables expressed as the mean with standard deviation or median with interquartile range according to their parametric distribution were used to compare demographic, clinical, and outcome characteristics. For all analyses, mortality and AKI were treated as categorical variables, and LOS was viewed as a continuous variable. Analysis of variance analysis was used to compare FO cohorts. Univariate and multivariate analyses of mortality were performed with logistic regression to determine independent predictors of mortality. Univariate and multivariate analyses of LOS utilized linear regression to assess the association of LOS with any independent predictors. For all analyses, variables that were statistically significant in the univariate analysis or that approached significance with a clinically relevant correlation were included in the multivariable model. Also, to adjust for in-hospital deaths and its potential bias in LOS analyses, we systematically assigned the LOS of patients who died to be the longest LOS in our study population + 1 day. Freedom from all-cause, in-hospital mortality was calculated by the Kaplan-Meier method. For our analyses, a $p$ value of $<0.05$ was considered to be statistically significant. Calculations were performed using the $\mathrm{R}$ stats package, version 2.15.2 (R Foundation, University of Auckland, New Zealand).

\section{Data availability}

The datasets during and/or analyzed during the current study are available from the corresponding author on reasonable request.

\section{Results}

During the study period, 167 neonates underwent congenital heart surgery classifiable by RACHS- 1 at our center. Of these patients, 48 were excluded because their surgery did not involve CPB and/or aortic cross-clamp, one patient was excluded due to insufficient clinical data, and one patient was excluded because pre-operative extracorporeal membrane oxygenation was required, leaving 117 neonates eligible for analysis. None of the patients had undergone previous cardiac surgery at an outside institution.

A total of $76(65 \%)$ neonates developed at least $10 \%$ FO. The demographic, clinical, and outcome characteristics of our study population separated into FO cohorts are given in Table 1. No difference was observed between the FO cohorts in terms of age, gender, race, weight, chromosomal abnormalities, RACHS-1 score, type of surgical repair, CPB time, and cross-clamp time. Hospital and CVICU LOS were longer in neonatal cohorts with more FO. Moderate/severe AKI (Stages 2 / 3) was more common in patients with greater FO (Fig. 1). Kaplan-Meier analysis showed that patients with greater FO were less likely to survive (Fig. 2).

The univariate and multivariate analyses of patients without AKI (Table 2) showed that FO was independently related to hospital and CVICU LOS [coefficient $0.322(p=0.029)$ and 0.468 ( $p<0.001)$, respectively]. A $1 \%$ increase in FO lengthened hospital LOS by 0.322 days and CVICU LOS by 0.468 days. Single ventricle palliation was also associated with total hospital and CVICU LOS [coefficient 13.05 ( $p=0.004)$ and $10.06(p=0.015)$, respectively], while CPB time was associated with hospital LOS (coffined 0.073; $p=0.03$ ).

Analyses of all patients regardless of AKI status (Tables 3, 4) showed that FO was independently associated with mortality and LOS. CPB time [Odds Ratio (OR) 1.042; 95\% confidence interval (CI) 1.09, 1.104; $p=0.019$ ], FO (OR 1.058; $95 \%$ CI 1.008, 1.125; $p=0.032$ ) and AKI Stage 3 (OR 79.12; 
Table 1 Characteristics of neonates undergoing cardiac surgery separated into fluid overload cohorts

\begin{tabular}{|c|c|c|c|c|c|}
\hline \multirow[t]{2}{*}{ Characteristics } & \multicolumn{3}{|l|}{ FO cohort } & \multirow[t]{2}{*}{ Overall } & \multirow[t]{2}{*}{$p$ value } \\
\hline & $<10 \%$ & $10-20 \%$ & $>20 \%$ & & \\
\hline Number of patients & 41 & 55 & 21 & 117 & \\
\hline Age (days) & $8[5,10]$ & $6[4,9]$ & $8[6,15]$ & $7[4,10]$ & 0.215 \\
\hline Gender, female & $20(48.8)$ & $22(40.0 \%)$ & $5(23.8 \%)$ & $47(40.2 \%)$ & 0.165 \\
\hline Race & & & & & 0.577 \\
\hline White & $32(78.0 \%)$ & $39(70.9 \%)$ & $18(85.7 \%)$ & $89(76.1 \%)$ & \\
\hline Black & $1(2.4)$ & $1(1.8 \%)$ & $1(4.8 \%)$ & $3(2.6 \%)$ & \\
\hline Native American & 0 & $2(3.6 \%)$ & $1(4.8 \%)$ & $3(2.6 \%)$ & \\
\hline Native Hawaiian/Pacific Islander & 0 & $1(1.8)$ & 0 & $1(0.9 \%)$ & \\
\hline Asian & $8(19.5 \%)$ & $11(20.0 \%)$ & $1(4.8 \%)$ & $20(17.1 \%)$ & \\
\hline Other & 0 & $1(1.8 \%)$ & 0 & $1(0.9 \%)$ & \\
\hline Ethnicity & & & & & $0.038 *$ \\
\hline Hispanic & $19(46.3 \%)$ & $23(41.8 \%)$ & $3(14.3 \%)$ & $45(38.5 \%)$ & \\
\hline Non-Hispanic & $22(53.7 \%)$ & $32(58.2 \%)$ & $18(85.7 \%)$ & $72(61.5 \%)$ & \\
\hline Weight at surgery $(\mathrm{kg})$ & $3.2 \pm 0.5$ & $3.2 \pm 0.6$ & $2.9 \pm 0.5$ & $3.1 \pm 0.6$ & 0.067 \\
\hline Pre-operative creatinine ${ }^{a}$ & $0.5[0.5,0.7]$ & $0.5[0.4,0.7]$ & $0.5[0.4,0.7]$ & $0.5[0.4,0.7]$ & 0.657 \\
\hline Chromosomal abnormality & & & & $19(16.2 \%)$ & 0.283 \\
\hline $22 q 11.2$ deletion & $4(9.8 \%)$ & $3(5.5 \%)$ & $2(9.5 \%)$ & & \\
\hline Trisomy 21 & $1(2.4 \%)$ & 0 & $2(9.5 \%)$ & & \\
\hline Other $^{\mathrm{b}}$ & $3(7.3 \%)$ & $4(7.3 \%)$ & 0 & & \\
\hline None & $33(80.5 \%)$ & $48(87.3 \%)$ & $17(81 \%)$ & & \\
\hline Prematurity & $7(17.1 \%)$ & $15(27.3 \%)$ & $10(47.6 \%)$ & $32(27.4 \%)$ & $0.038^{*}$ \\
\hline RACHS-1 score & & & & & 0.098 \\
\hline Category 1 & $1(2.4 \%)$ & 0 & 0 & $1(0.9 \%)$ & \\
\hline Category 2 & $2(4.9 \%)$ & $4(7.3 \%)$ & $6(28.6 \%)$ & $12(10.3 \%)$ & \\
\hline Category 3 & $9(30.0 \%)$ & $10(18.2 \%)$ & $3(14.3 \%)$ & $22(18.8 \%)$ & \\
\hline Category 4-6 & $29(70.7 \%)$ & $41(70.9 \%)$ & $12(57.1 \%)$ & $82(68.4 \%)$ & \\
\hline Type of repair & & & & & 0.653 \\
\hline Single ventricle palliation & $8(19.5 \%)$ & $13(23.6 \%)$ & $3(14.3 \%)$ & $24(20.5 \%)$ & \\
\hline Two ventricle repair & $33(80.8 \%)$ & $42(76.4 \%)$ & $18(85.7 \%)$ & $93(79.9 \%)$ & \\
\hline Cardiopulmonary bypass time (min) & $146[116,176]$ & $161[129,177]$ & $160[138,185]$ & $156[124,183]$ & 0.314 \\
\hline Cross-clamp time (min) & $83[59,97]$ & $61[84,163]$ & $96[77,110]$ & $85[63,104]$ & 0.354 \\
\hline Vasoactive-inotrope score & $7.5[5,9.5]$ & $8[5,11]$ & $10[7.5,14]$ & $8[5,11]$ & $0.012 *$ \\
\hline Mortality & $1(2.4 \%)$ & $4(7.3 \%)$ & $4(19 \%)$ & $9(7.7 \%)$ & 0.066 \\
\hline Cardiovascular intensive care unit LOS (days) & $9[7,17]$ & $10[7,16]$ & $20[10,42]$ & $10[7,19]$ & $0.026 *$ \\
\hline Hospital LOS (days) & $16[11,24]$ & $16[13,25]$ & $33[16,45]$ & $17[12,30]$ & $0.047 *$ \\
\hline Acute kidney injury & & & & & $0.013 *$ \\
\hline No injury & $23(56.1 \%)$ & $22(40 \%)$ & $5(23.8 \%)$ & $50(43.1 \%)$ & \\
\hline Stage 1 & $14(34.1 \%)$ & $22(40 \%)$ & $5(23.8 \%)$ & $41(35.3 \%)$ & \\
\hline Stage 2 & $3(7.3 \%)$ & $8(14.8 \%)$ & $8(38.1 \%)$ & $19(16.4 \%)$ & \\
\hline Stage 3 & $1(2.4 \%)$ & $2(3.7 \%)$ & $3(14.3 \%)$ & $6(5.2 \%)$ & \\
\hline
\end{tabular}

*Statistically significant at $p<0.05$

Data in table are presented as the median with the interquartile range (IQR) in square brackets, as a number with or without the percentage in parenthesis or as the mean \pm standard deviation (SD)

FO Fluid overload, RACHS-1 Risk Adjustment for Congenital Heart Surgery 1 method LOS length of stay

${ }^{a}$ One patient in the 10-20\% fluid overload cohort had insufficient acute kidney injury data (no pre-operative creatinine measures due to emergent surgery)

${ }^{\mathrm{b}} 45 \mathrm{X}$ and deletion/duplication variants were detected on comparative genomic hybridization 


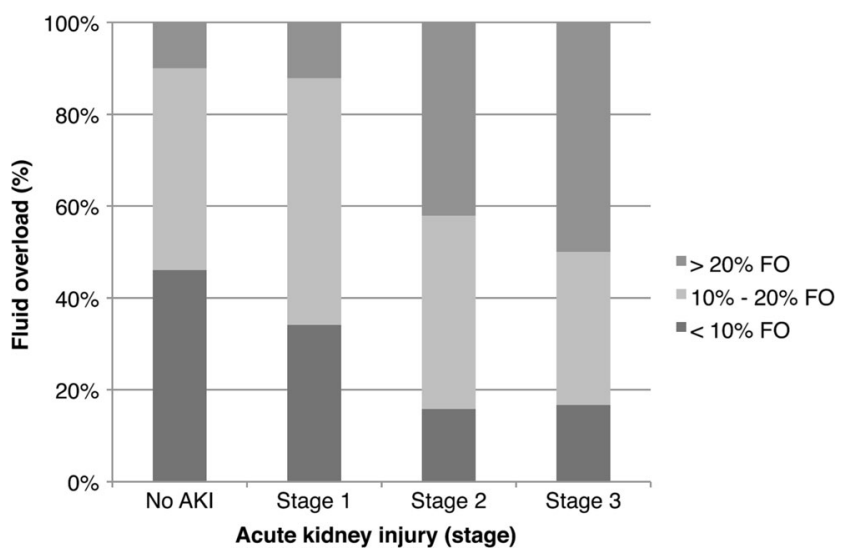

Fig. 1 Stacked column graph showing the percentage of neonates following cardiac surgery by fluid overload (FO) cohort within each acute kidney injury (AKI) stage

$95 \%$ CI $2.879,1.3 \times 10^{4} ; p=0.028$ ) were independently associated with mortality (Table 3). A $1 \%$ increase in FO conferred a $5.8 \%$ greater odds of mortality. Similarly, FO was independently associated with total hospital and CVICU LOS [coefficient $0.474(p<0.001)$ and $0.439(p<0.001)$, respectively], as were neonates undergoing single ventricle palliation [coefficient $23.06(p=0.005)$ and 16.55 $(p=0.035)$, respectively] and longer CPB time [coefficient $0.258(p=<0.001)$ and $0.255(p<0.001)$, respectively] (Table 4). A $1 \%$ increase in FO conveyed an extra 0.474 total hospital and 0.439 CVICU days. AKI Stage 3 was also associated with total hospital and CVICU LOS [coefficient 104.7 $(p<0.001)$ and $83.23(p<0.001)$, respectively].



Fig. 2 Kaplan-Meier survival analysis of neonates following cardiac surgery according to fluid overload (FO) cohort. Data are presented as cumulative survival based on a patient's maximum aggregate FO experienced between postoperative days $0-5$, used to categorize patients into $<10 \%, 10-20 \%$, and $>20 \%$ FO cohorts

\section{Discussion}

Our study found that FO occurs in a majority of neonates following congenital heart surgery with $\mathrm{CPB}$ and aortic cross-clamp and that it is associated with significant morbidity and poor outcomes. We found that this association remained true after controlling for AKI.

Our study offers a novel perspective on the role of FO by isolating its effects from those of $\mathrm{AKI}$ - a distinction that prior studies have not made and, consequently the separate contributions of FO and AKI toward clinical outcomes in patients following congenital heart surgery were unclear. While AKI has been shown to be associated with poor outcomes, it is unrecognized whether FO from CPB and cardiac surgery has important clinical implications independent of AKI. Previous studies are limited largely due to the colinearity of these overlapping and interacting clinical processes. Our study differs from these studies in that we evaluated a subgroup of patients without AKI to determine the effect of FO in the absence of AKI. Prior studies are also limited by broad age considerations and small sample sizes. Sampaio et al. [15] found that maximum FO is associated with the duration of mechanical ventilation and intensive care LOS. However, more than one-third of their patients experienced concurrent renal failure. Lex and colleagues [7] found that a higher FO on postoperative day 0 was associated with mortality and low cardiac output syndrome, but at the same time these authors reported that higher maximum creatinine levels were associated with a higher risk of $>5 \% \mathrm{FO}$ by the end of postoperative day 2 . Wilder et al. [16] found that both a FO $>16 \%$ and creatinine $>$ $0.9 \mathrm{mg} / \mathrm{dL}$ on postoperative day 3 are concomitantly associated with a composite poor outcome score. However, their report did not intend to separate the independent effects of FO as most of their patients (71\%) had AKI Stage 1 or greater, and neonates with poor outcomes had a higher peak and postoperative day 3 creatinine. Additionally, a number of other studies reporting an association between FO and poor outcomes [1, 5, 6] do not demonstrate the independent contribution of FO. The aim of our study was to evaluate $\mathrm{FO}$ in a unique fashion, apart from AKI, in a large, exclusively neonatal population.

Our findings are consistent with previous reports suggesting that FO is associated with poor outcomes. We found that neonates with $>20 \% \mathrm{FO}$ tended to stay 11 days longer in the CVICU and 17 days longer in the hospital than neonates who experienced $<10 \%$ FO. These data are similar to the results reported by Wilder and colleagues [16] who found that patients with $\geq 16 \%$ FO on postoperative day 3 on average stayed 11 days in the intensive care unit and 20 days in the hospital compared to 7 and 15 days, respectively, in those with $<16 \%$ FO. Our findings are in agreement with previous reports that longer CPB times [29] and single ventricle palliation [30] predispose to poor outcomes. 
Table 2 Univariate and multivariate predictors of hospital and cardiovascular intensive care unit lengths of stay among neonates without acute kidney injury following cardiac surgery

\begin{tabular}{|c|c|c|c|c|c|c|c|c|}
\hline \multirow[t]{3}{*}{ Characteristics } & \multicolumn{4}{|c|}{ Hospital length of stay } & \multicolumn{4}{|c|}{ Cardiovascular intensive care unit length of stay } \\
\hline & \multicolumn{2}{|c|}{ Univariate analysis } & \multicolumn{2}{|c|}{ Multivariate analysis } & \multicolumn{2}{|c|}{ Univariate analysis } & \multicolumn{2}{|c|}{ Multivariate analysis } \\
\hline & Coefficient $\mathrm{a}^{\mathrm{a}}$ & $p$ value & Coefficient $^{\mathrm{a}}$ & $p$ value & Coefficient $\mathrm{t}^{\mathrm{a}}$ & $p$ value & Coefficient $\mathrm{t}^{\mathrm{a}}$ & $p$ value \\
\hline Age (days) & -0.73 & $0.01 *$ & -0.36 & 0.106 & -0.63 & $0.016^{*}$ & -0.31 & 0.128 \\
\hline Gender (female) & -1.89 & 0.68 & & & -3.63 & 0.382 & & \\
\hline Race $^{\mathrm{a}}$ & & $>0.05$ & & & & $>0.05$ & & \\
\hline Ethnicity (Hispanic) & 1.27 & 0.772 & & & -0.6 & 0.881 & & \\
\hline Weight at surgery $(\mathrm{kg})$ & 2.15 & 0.537 & & & -0.64 & 0.84 & & \\
\hline Chromosomal abnormality & 2.69 & 0.633 & & & 0.8 & 0.876 & & \\
\hline Prematurity & 16.57 & $<0.001 *$ & 7.016 & 0.093 & 13.95 & $0.001 *$ & 4.26 & 0.26 \\
\hline RACHS-1 score ${ }^{b}$ & & $>0.05$ & & & & $>0.05$ & & \\
\hline Type of repair (single ventricle) & 16.77 & $0.002 *$ & 13.05 & $0.004 *$ & -12.11 & $0.015 *$ & 10.06 & $0.015^{*}$ \\
\hline Cardiopulmonary bypass time (min) & 0.14 & $<0.001 *$ & 0.073 & $0.03 *$ & 0.12 & $0.001 *$ & 0.059 & 0.056 \\
\hline Cross-clamp time (min) & 0.03 & 0.558 & & & 0.02 & 0.646 & & \\
\hline Vasoactive-inotrope score & 0.76 & 0.139 & & & 0.4 & 0.397 & & \\
\hline $\mathrm{FO}(\%)$ & 0.46 & $0.009 *$ & 0.322 & $0.029 *$ & 0.56 & $<0.001 *$ & 0.468 & $<0.001 *$ \\
\hline
\end{tabular}

*Statistically significant at $p<0.05$

${ }^{\text {a }}$ Days of increased length of stay per one unit increment of characteristic (independent variable)

${ }^{\mathrm{b}}$ Reference levels: Race (Asian); Risk Adjustment for Congenital Heart Surgery-1 RACHS-1 (score = 1), FO fluid overload

We found that the effects of FO are clinically important independent of the development of AKI, leading us to speculate that the development of postoperative FO in the absence of AKI occurs, in part, due to several peri-operative factors, including fluid/blood product administration, hemodilution and hemoconcentration [31], low oncotic pressure, capillary hyperpermeability, and low cardiac output, culminating into systemic endothelial dysfunction. Evidence of inflammation driving capillary leak syndrome following CPB can often be detected before the clinical manifestations are evident [32]. However, tissue measurements of inflammation are not commonly available or utilized, and serum markers are varied, indiscriminante, and non-specific [33]. Clinical and readily available biomarkers to predict FO in the vulnerable neonate patient population have yet to be elucidated, yet the prediction of FO may have important prognostic and therapeutic implications.

Our findings suggest that the early identification of postoperative FO may predict risk and that strategies to prevent or treat neonates with FO may have benefit in improving outcomes. More conservative fluid resuscitation may be valuable, as the common practice of administering fluid boluses for borderline low blood pressure in the early postoperative setting may not be as benign as previously understood, especially if the clinical indices of perfusion are normal. Although the role of diuretics in the setting of AKI is controversial [34], early prophylactic or therapeutic decongestive therapies for FO may be a modifiable feature in neonatal postoperative fluid management, even in patients without evidence of AKI. Initial studies have found that passive peritoneal drainage and peritoneal dialysis are associated with earlier and greater negative fluid balance [35], increased urine output, earlier extubation, improved inotrope scores [36, 37], lower electrolyte abnormality scores, and greater avoidance of $10 \%$ FO [38] and that peritoneal dialysis and early continuous renal replacement therapy are associated with decreased mortality $[39,40]$. This growing body of evidence suggests that more aggressive forms of fluid removal initiated early in the postoperative course may be potential avenues for future investigation. Similarly, although studies to date do not demonstrate the efficacy of agents such as fenoldopam [41] and aminophylline [42] to prevent AKI after cardiac surgery, future study of prophylactic medicinal therapies for FO may be warranted.

Our study has important limitations. First, it has a retrospective cohort design which carries intrinsic risk for confounding and bias and thus cannot infer causality. Second, it is based on experience from a single institution and may not be generalizable to other hospitals. For example, we do not perform modified ultrafiltration during or after CPB at our hospital, and we do not routinely administer steroids in the 
Table 3 Univariate and multivariate predictors of in-hospital mortality among neonates following cardiac surgery

\begin{tabular}{|c|c|c|c|c|c|}
\hline \multirow[t]{2}{*}{ Characteristics } & \multicolumn{3}{|l|}{ Univariate analysis } & \multicolumn{2}{|l|}{ Multivariate analysis } \\
\hline & Survivors $(n=108)$ & Nonsurvivors $(n=9)$ & $p$ value & $\begin{array}{l}\text { Odds ratio } \\
\text { (95\% confidence interval) }\end{array}$ & $p$ value \\
\hline Age (days) & $4.6[1.7,7.4]$ & $6.7[3.7,10.4]$ & 0.116 & & \\
\hline Gender (female) & $42(38.9 \%)$ & $5(55.6 \%)$ & 0.481 & & \\
\hline Race & & & 0.333 & & \\
\hline White & $81(75 \%)$ & $8(88.9 \%)$ & & & \\
\hline Black & $3(2.8 \%)$ & 0 & & & \\
\hline Native American & $2(1.9 \%)$ & $1(11.1 \%)$ & & & \\
\hline Native Hawaiian/Pacific Islander & $1(0.9 \%)$ & 0 & & & \\
\hline Asian & $20(18.5 \%)$ & 0 & & & \\
\hline Other & $1(0.9 \%)$ & 0 & & & \\
\hline Ethnicity & & & 0.732 & & \\
\hline Hispanic & $41(38 \%)$ & $4(44.4 \%)$ & & & \\
\hline Non-Hispanic & $67(62 \%)$ & $5(55.6 \%)$ & & & \\
\hline Weight at surgery $(\mathrm{kg})$ & $3.2 \pm 0.6$ & $2.8 \pm 0.5$ & 0.054 & $0.127(0.003,19.8)$ & 0.182 \\
\hline Chromosomal abnormality & & & 0.236 & & \\
\hline 22q11.2 deletion & $9(8.3 \%)$ & 0 & & & \\
\hline Trisomy 21 & $2(1.9 \%)$ & $1(11.1 \%)$ & & & \\
\hline Other $^{b}$ & $6(5.6 \%)$ & $1(11.1 \%)$ & & & \\
\hline None & $91(84.3 \%)$ & $7(77.8 \%)$ & & & \\
\hline Prematurity & $27(25 \%)$ & $5(55.6 \%)$ & 0.062 & $0.131(0.002,3.063)$ & 0.269 \\
\hline RACHS-1 score & & & 0.234 & & \\
\hline 1 & $1(0.9 \%)$ & 0 & & & \\
\hline 2 & $10(9.3 \%)$ & $2(22.2 \%)$ & & & \\
\hline 3 & $22(20.4 \%)$ & 0 & & & \\
\hline $4-6$ & $75(69.4 \%)$ & $7(77.8 \%)$ & & & \\
\hline Type of repair & & & 0.387 & & \\
\hline Single ventricle palliation & $21(19.4 \%)$ & $3(33.3 \%)$ & & & \\
\hline Two ventricle repair & $87(80.6 \%)$ & $6(66.7 \%)$ & & & \\
\hline Cardiopulmonary bypass time (min) & $150[121,176]$ & $233[175,257]$ & $<0.001 *$ & $1.042(1.09,1.104)$ & $0.019^{*}$ \\
\hline Cross-clamp time (min) & $84[59,103.2]$ & $93[77,114]$ & 0.229 & & \\
\hline Vasoactive-inotrope score & $8[5.5,11]$ & $7[0,11.5]$ & 0.452 & & \\
\hline $\mathrm{FO}(\%)$ & $12[8,17]$ & $18.5[15.3,53.5]$ & $0.008 *$ & $1.058(1.008,1.125)$ & $0.032 *$ \\
\hline Acute kidney injury & & & $<0.001 *$ & & \\
\hline No & $48(44.9 \%)$ & $2(22.2 \%)$ & & & \\
\hline Stage 1 & $38(35.5 \%)$ & $3(33.3 \%)$ & & $1.317(0.081,31.9)$ & 0.844 \\
\hline Stage 2 & $19(17.8 \%)$ & $0(0 \%)$ & & $0\left(\mathrm{NA}, 1.6 \times 10^{118}\right)$ & 0.995 \\
\hline Stage 3 & $2(1.9 \%)$ & $4(44.4 \%)$ & & $79.12\left(2.879,1.3 \times 10^{4}\right)$ & $0.028 *$ \\
\hline
\end{tabular}

RACHS Risk Adjustment for Congenital Heart Surgery, FO fluid overload

*Statistically significant at $p<0.05$

Data in table are presented as the median with the IQR in square brackets, as a number with the percentage in parenthesis or as the mean $\pm \mathrm{SD}$

${ }^{a}$ Odds ratio per one unit increment of characteristic (independent variable)

${ }^{\mathrm{b}} 45 \mathrm{X}$ and deletion/duplication variants detected on comparative genomic hybridization

postoperative period, which may have an influence on our observation of FO and LOS. However, previous studies have shown that modified ultrafiltration does not selectively remove proinflammatory mediators, result in end-organ 
Table 4 Univariate and multivariate predictors of hospital and cardiovascular intensive care unit lengths of stay among neonates following cardiac surgery

\begin{tabular}{|c|c|c|c|c|c|c|c|c|}
\hline \multirow[t]{3}{*}{ Characteristics } & \multicolumn{4}{|c|}{ Hospital length of stay } & \multicolumn{4}{|c|}{ Cardiovascular intensive care unit length of stay } \\
\hline & \multicolumn{2}{|c|}{ Univariate analysis } & \multicolumn{2}{|c|}{ Multivariate analysis } & \multicolumn{2}{|c|}{ Univariate analysis } & \multicolumn{2}{|c|}{ Multivariate analysis } \\
\hline & Coefficient $\mathrm{t}^{\mathrm{a}}$ & $p$ value & Coefficient ${ }^{\mathrm{a}}$ & $p$ value & Coefficient $\mathrm{t}^{\mathrm{a}}$ & $p$ value & Coefficient $^{\mathrm{a}}$ & $p$ value \\
\hline Age (days) & -1.39 & 0.051 & & & -1.18 & 0.065 & & \\
\hline Gender (female) & 19.78 & $0.034^{*}$ & 11.72 & 0.083 & 16.62 & $0.048 *$ & 8.3 & 0.199 \\
\hline Race $^{\mathrm{a}}$ & & $>0.05$ & & & & $>0.05$ & & \\
\hline Ethnicity (Hispanic) & 7.57 & 0.426 & & & 3.93 & 0.645 & & \\
\hline Weight at surgery $(\mathrm{kg})$ & -17.87 & $0.021^{*}$ & -0.89 & 0.888 & -18.04 & $0.009 *$ & -5.31 & 0.382 \\
\hline Chromosomal abnormality & 6.95 & 0.579 & & & 5.75 & 0.61 & & \\
\hline Prematurity & 34.35 & $0.001 *$ & 7.55 & 0.394 & 28.56 & $0.002 *$ & 1.64 & 0.847 \\
\hline RACHS-1 score ${ }^{b}$ & & $>0.05$ & & & & $>0.05$ & & \\
\hline Type of repair (single ventricle) & 31.25 & $0.006^{*}$ & 23.06 & $0.005^{*}$ & 22.74 & $0.025^{*}$ & 16.55 & $0.035^{*}$ \\
\hline Cardiopulmonary bypass time (min) & 0.48 & $<0.001^{*}$ & 0.258 & $<0.001 *$ & 0.43 & $<0.001 *$ & 0.255 & $<0.001 *$ \\
\hline Cross-clamp time (min) & 0.16 & 0.234 & & & 0.14 & 0.254 & & \\
\hline Vasoactive-inotrope score & -0.51 & 0.642 & & & -0.59 & 0.549 & & \\
\hline $\mathrm{FO}(\%)$ & 0.62 & $<0.001^{*}$ & 0.474 & $<0.001 *$ & 0.57 & $<0.001 *$ & 0.439 & $<0.001 *$ \\
\hline \multicolumn{9}{|l|}{ Acute kidney injury ${ }^{\mathrm{a}}$} \\
\hline Stage 1 & 7.89 & 0.371 & -1.53 & 0.832 & 7.74 & 0.347 & -0.623 & 0.928 \\
\hline Stage 2 & 16.14 & 0.154 & 12.29 & 0.177 & 14.15 & 0.18 & 10.206 & 0.242 \\
\hline Stage 3 & 129.64 & $<0.001^{*}$ & 104.7 & $<0.001 *$ & 106.8 & $<0.001 *$ & 83.23 & $<0.001 *$ \\
\hline
\end{tabular}

*Statistically significant at $p<0.05$

${ }^{a}$ Days of increased length of stay per one unit increment of characteristic (independent variable)

${ }^{\mathrm{b}}$ Reference levels: Race (Asian), Risk Adjustment for Congenital Heart Surgery-1 RACHS-1 (Score = 1), Acute Kidney Injury (No Acute Kidney Injury), $F O$ fluid overload

function improvements, or change morbidity and mortality [43], and the utilization of steroids in the postoperative period continues to be a controversial practice [44]. Third, our calculation of FO does not account for insensible losses, whereas the FO calculation based on daily weight does. We do not obtain daily weights in neonates in the immediate postoperative period at our hospital due to patient acuity, risk to patient, and inaccuracy due to indwelling lines and tubes. Fourth, our AKI definition used the KDIGO creatinine criteria, but not the urine output criteria. It is possible that there were patients with AKI whom we did not detect; creatinine is an insensitive marker of renal injury [45], and it is possible FO may have had a dilution effect on serum creatinine concentration, thus masking AKI events [46]. Either of these effects could have obscured the influence of AKI on outcomes. More abstractly, FO and AKI are certainly intertwined and often impact each other. At the same time, there are also scenarios in which FO and AKI manifest in the absence of the other. Our study has attempted to identify the separate impact of these two phenomena, but it may be limited due to the interwoven relationship between FO and AKI. Finally, our subgroup mortality analyses may not have reached significance due to inadequate power from sample size limitations.

$\mathrm{FO}$, independent from AKI, is a significant risk factor for poor postoperative outcomes in neonates recovering from cardiac surgery with CPB and aortic cross-clamp. Future investigations of decongestive therapies, even in fluid-overloaded patients without AKI, may be important in understanding optimal postoperative fluid management strategies. In these future investigations, FO may be an important marker to characterize disease severity.

\section{Conclusions}

Fluid overload is an important independent contributor to outcomes in neonates following congenital heart surgery with cardiopulmonary bypass. Careful fluid management after cardiac surgery in neonates with and without AKI is warranted. 
Acknowledgements This study was supported by the Cardiovascular Intensive Care Unit (CVICU) Fund, Heart Center at Lucile Packard Children's Hospital Stanford, Stanford University School of Medicine (principal investigator, A.Y.S.)

\section{Compliance with ethical standards}

Conflict of interest The authors declare they have no conflict of interest.

Ethical approval All procedures performed in studies involving human participants were in accordance with the ethical standards of the institutional and/or national research committee and with the 1964 Helsinki declaration and its later amendments or comparable ethical standards.

Informed consent For this type of study formal consent is not required.

\section{References}

1. Hazle MA, Gajarski RJ, Yu S, Donohue J, Blatt NB (2013) Fluid overload in infants following congenital heart surgery. Pediatr Crit Care Med 14:44-49

2. Arikan AA, Zappitelli M, Goldstein SL, Naipaul A, Jefferson LS, Loftis LL (2012) Fluid overload is associated with impaired oxygenation and morbidity in critically ill children. Pediatr Crit Care Med 13:253-258

3. Sutherland SM, Zappitelli M, Alexander SR, Chua AN, Brophy PD, Bunchman TE, Hackbarth R, Somers MJ, Baum M, Symons JM, Flores FX, Benfield M, Askenazi D, Chand D, Fortenberry JD, Mahan JD, McBryde K, Blowey D, Goldstein S (2010) Fluid overload and mortality in children receiving continuous renal replacement therapy: the Prospective Pediatric Continuous Renal Replacement Therapy Registry. Am J Kidney Dis 55:316-325

4. Goldstein SL, Currier H, Graf JM, Cosio CC, Brewer ED, Sachdeva R (2001) Outcome in children receiving continuous venovenous hemofiltration. Pediatrics 107:1309-1312

5. Hassinger AB, Wald EL, Goodman DM (2014) Early postoperative fluid overload precedes acute kidney injury and is associated with higher morbidity in pediatric cardiac surgery patients. Pediatr Crit Care Med 15:131-138

6. Piggott KD, Soni M, Decampli WM, Ramirez JA, Holbein D, Fakioglu H, Blanco CJ, Pourmoghadam KK (2015) Acute kidney injury and fluid overload in neonates following surgery for congenital heart disease. World J Pediatr Congenit Heart Surg 6:401-406

7. Lex DJ, Tóth R, Czobor NR, Alexander SI, Breuer T, Sápi E, Szatmári A, Székely E, Gál J, Székely A (2016) Fluid overload is associated with higher mortality and morbidity in pediatric patients undergoing cardiac surgery. Pediatr Crit Care Med 17:307-314

8. Grist G, Whittaker C, Merrigan K, Fenton J, Worrall E, O'Brien J, Lofland G (2011) The correlation of fluid balance changes during cardiopulmonary bypass to mortality in pediatric and congenital heart surgery patients. J Extra Corpor Technol 43:215-226

9. Day JRS, Taylor KM (2005) The systemic inflammatory response syndrome and cardiopulmonary bypass. Int J Surg 3:129-140

10. Warren OJ, Smith AJ, Alexiou C, Rogers PL, Jawad N, Vincent C, Darzi AW, Athanasiou T (2009) The inflammatory response to cardiopulmonary bypass: part $1-$ mechanisms of pathogenesis. $\mathrm{J}$ Cardiothorac Vasc Anesth 23:223-231

11. Seghaye M-C, Grabitz RG, Duchateau J, Busse S, Däbritz S, Koch D, Alzen G, Hörnchen H, Messmer BJ, Von Bernuth G (1996) Inflammatory reaction and capillary leak syndrome related to cardiopulmonary bypass in neonates undergoing cardiac operations. J Thorac Cardiovasc Surg 112:687-697

12. Blinder JJ, Goldstein SL, Lee VV, Baycroft A, Fraser CD, Nelson D, Jefferies JL (2012) Congenital heart surgery in infants: effects of acute kidney injury on outcomes. J Thorac Cardiovasc Surg 143: 368-374

13. Lassnigg A, Schmidlin D, Mouhieddine M, Bachmann LM, Druml W, Bauer P, Hiesmayr M (2004) Minimal changes of serum creatinine predict prognosis in patients after cardiothoracic surgery: a prospective cohort study. J Am Soc Nephrol 15:1597-1605

14. Zappitelli M, Bernier P-L, Saczkowski RS, Tchervenkov CI, Gottesman R, Dancea A, Hyder A, Alkandari O (2009) A small post-operative rise in serum creatinine predicts acute kidney injury in children undergoing cardiac surgery. Kidney Int 76:885-892

15. Sampaio TZAL, O'Hearn K, Reddy D, Menon K (2015) The influence of fluid overload on the length of mechanical ventilation in pediatric congenital heart surgery. Pediatr Cardiol 36:1692-1699

16. Wilder NS, Yu S, Donohue JE, Goldberg CS, Blatt NB (2016) Fluid overload is associated with late poor outcomes in neonates following cardiac surgery. Pediatr Crit Care Med 17:420-427

17. Nicholson GT, Clabby ML, Mahle WT (2014) Is there a benefit to postoperative fluid restriction following infant surgery? Congenit Heart Dis 9:529-535

18. Jenkins KJ, Gauvreau K, Newburger JW, Spray TL, Moller JH, Iezzoni LI (2002) Consensus-based method for risk adjustment for surgery for congenital heart disease. J Thorac Cardiovasc Surg 123:110-118

19. Gaies MG, Gurney JG, Yen AH, Napoli ML, Gajarski RJ, Ohye RG, Charpie JR, Hirsch JC (2010) Vasoactive-inotropic score as a predictor of morbidity and mortality in infants after cardiopulmonary bypass. Pediatr Crit Care Med 11:234-238

20. Davidson J, Tong S, Hancock H, Hauck A, da Cruz E, Kaufman J (2012) Prospective validation of the vasoactive-inotropic score and correlation to short-term outcomes in neonates and infants after cardiothoracic surgery. Intensive Care Med 38:1184-1190

21. Holliday MA, Segar WE (1957) The maintenance need for water in parenteral fluid therapy. Pediatrics 19:823-832

22. Lex DJ, Tóth R, Cserép Z, Alexander SI, Breuer T, Sápi E, Szatmári A, Székely E, Gál J, Székely A (2014) A comparison of the Systems for the Identification of postoperative acute kidney injury in pediatric cardiac patients. Ann Thorac Surg 97:202-210

23. Sutherland SM, Byrnes JJ, Kothari M, Longhurst CA, Dutta S, Garcia P, Goldstein SL (2015) AKI in hospitalized children: comparing the pRIFLE, AKIN, and KDIGO definitions. Clin J Am Soc Nephrol 10:554-561

24. Jetton JG, Guillet R, Askenazi DJ, Dill L, Jacobs J, Kent AL, Selewski DT, Abitbol CL, Kaskel FJ, Mhanna MJ, Ambalavanan N, Charlton JR, Neonatal Kidney Collaborative (2016) Assessment of worldwide acute kidney injury epidemiology in neonates: Design of a Retrospective Cohort Study. Front Pediatr 4:68

25. Selewski DT, Charlton JR, Jetton JG, Guillet R, Mhanna MJ, Askenazi DJ, Kent AL (2015) Neonatal acute kidney injury. Pediatrics 136:e463-e473

26. Jetton JG, Askenazi DJ (2014) Acute kidney injury in the neonate. Clin Perinatol 41:487-502

27. Kaddourah A, Basu RK, Bagshaw SM, Goldstein SL, AWARE Investigators (2017) Epidemiology of acute kidney injury in critically ill children and young adults. N Engl J Med 376:11-20

28. Selewski DT, Cornell TT, Lombel RM, Blatt NB, Han YY, Mottes T, Kommareddi M, Kershaw DB, Shanley TP, Heung M (2011) Weight-based determination of fluid overload status and mortality in pediatric intensive care unit patients requiring continuous renal replacement therapy. Intensive Care Med 37:1166-1173

29. Pawade A, Waterson K, Laussen P, Karl TR, Mee RB (1993) Cardiopulmonary bypass in neonates weighing less than $2.5 \mathrm{~kg}$ : 
analysis of the risk factors for early and late mortality. J Card Surg $8: 1-8$

30. Centers for Disease Control and Prevention (2007) Hospital stays, hospital charges, and in-hospital deaths among infants with selected birth defects-United States, 2003. MMWR Morb Mortal Wkly Rep 56:25-29

31. Siehr SL, Shi S, Hao S, Hu Z, Jin B, Hanley F, Reddy VM, McElhinney DB, Ling XB, Shin AY (2016) Exploring the role of polycythemia in patients with cyanosis after palliative congenital heart surgery. Pediatr Crit Care Med 17:216-222

32. Kubicki R, Grohmann J, Siepe M, Benk C, Humburger F, RensingEhl A, Stiller B (2013) Early prediction of capillary leak syndrome in infants after cardiopulmonary bypass. Eur J Cardiothorac Surg 44:275-281

33. Kozik DJ, Tweddell JS (2006) Characterizing the inflammatory response to cardiopulmonary bypass in children. Ann Thorac Surg 81:S2347-S2354

34. Ricci Z, Haiberger R, Pezzella C, Garisto C, Favia I, Cogo P (2015) Furosemide versus ethacrynic acid in pediatric patients undergoing cardiac surgery: a randomized controlled trial. Crit Care 19:1-9

35. Saini A, Delius RE, Seshadri S, Walters H 3rd, Mastropietro CW (2012) Passive peritoneal drainage improves fluid balance after surgery for congenital heart disease. Eur J Cardio-Thorac Surg 41: 256-260

36. Kwiatkowski DM, Menon S, Krawczeski CD, Goldstein SL, Morales DL, Phillips A, Manning PB, Eghtesady P, Wang Y, Nelson DP, Cooper DS (2015) Improved outcomes with peritoneal dialysis catheter placement after cardiopulmonary bypass in infants. J Thorac Cardiovasc Surg 149:230-236

37. Sorof JM, Stromberg D, Brewer ED, Feltes TF, Fraser CD Jr (1999) Early initiation of peritoneal dialysis after surgical repair of congenital heart disease. Pediatr Nephrol 13:641-645

38. Kwiatkowski DM, Goldstein SL, Cooper DS, Nelson DP, Morales DL, Krawczeski CD (2017) Peritoneal dialysis vs furosemide for prevention of fluid overload in infants after cardiac surgery: a randomized clinical trial. JAMA Pediatr 171:357-364

39. Bojan M, Gioanni S, Vouhé PR, Journois D, Pouard P (2012) Early initiation of peritoneal dialysis in neonates and infants with acute kidney injury following cardiac surgery is associated with a significant decrease in mortality. Kidney Int 82:474-481

40. Sanchez-de-Toledo J, Perez-Ortiz A, Gil L, Baust T, Linés-Palazón M, Perez-Hoyos S, Gran F, Abella RF (2015) Early initiation of renal replacement therapy in pediatric heart surgery is associated with lower mortality. Pediatr Cardiol 37:623-628

41. Bove T, Zangrillo A, Guarracino F, Alvaro G, Persi B, Maglioni E, Galdieri N, Comis M, Caramelli F, Pasero DC, Pala G, Renzini M, Conte M, Paternoster G, Martinez B, Pinelli F, Frontini M, Zucchetti MC, Pappalardo F, Amantea B, Camata A, Pisano A, Verdecchia C, Dal Checco E, Cariello C, Faita L, Baldassarri R, Scandroglio AM, Saleh O, Lembo R, Calabrò MG, Bellomo R, Landoni $G$ (2014) Effect of fenoldopam on use of renal replacement therapy among patients with acute kidney injury after cardiac surgery: a randomized clinical trial. JAMA 312:2244-2253

42. Axelrod DM, Sutherland SM, Anglemyer A, Grimm PC, Roth SJ (2016) A double-blinded, randomized, placebo-controlled clinical trial of aminophylline to prevent acute kidney injury in children following congenital heart surgery with cardiopulmonary bypass. Pediatr Crit Care Med 17:135-143

43. Lang SM, Syed MA, Dziura J, Rocco E, Kirshbom P, Bhandari V, Giuliano JS Jr (2014) The effect of modified ultrafiltration on angiopoietins in pediatric cardiothoracic operations. Ann Thorac Surg 98:1699-1704

44. Pasquali SK, Li JS, He X, Jacobs ML, O'Brien SM, Hall M, Jaquiss RD, Welke KF, Peterson ED, Shah SS, Gaynor JW, Jacobs JP (2012) Perioperative methylprednisolone and outcome in neonates undergoing heart surgery. Pediatrics 129:e385-e391

45. McCullough PA, Bouchard J, Waikar SS, Siew ED, Endre ZH, Goldstein SL, Koyner JL, Macedo E, Doi K, Di Somma S, Lewington A, Thadhani R, Chakravarthi R, Ice C, Okusa MD, Duranteau J, Doran P, Yang L, Jaber BL, Meehan S, Kellum JA, Haase M, Murray PT, Cruz D, Maisel A, Bagshaw SM, Chawla LS, Mehta RL, Shaw AD, Ronco C (2013) Implementation of novel biomarkers in the diagnosis, prognosis, and management of acute kidney injury: executive summary from the tenth consensus conference of the acute dialysis quality initiative (ADQI). In: McCullough PA, Kellum JA, Mehta RL et al. (eds) Contribribution to Nephrology, vol 182. S. Karger AG, Basel, pp 5-12

46. Basu RK, Andrews A, Krawczeski C, Manning P, Wheeler DS, Goldstein SL (2013) Acute kidney injury based on corrected serum creatinine is associated with increased morbidity in children following the arterial switch operation. Pediatr Crit Care Med 14:e218-e224 